\title{
Spontaneous extrusion of the peritoneal catheter through the intact abdominal wall: report of two cases
}

\author{
Carlos Umberto Pereira ${ }^{1}$, Gabriela Ferreira Kalkmann, Humberto Belém de Aquino
}

\begin{abstract}
${ }^{1}$ Departament of Neurosurgery, Sergipe Emergency Hospital. Preceptor of the Neurosurgery Residency at Surgery Hospital Charitable Foundation. Aracaju - Sergipe, Brasil.

${ }^{2}$ Medical Students at Federal University of Paraná. Curitiba - Paraná, Brasil.

${ }^{3}$ Pediatric Neurosurgeon, Dr. José de Carvalho Hospital. São José dos Campos - São Paulo, Brasil.
\end{abstract}

To whom correspondence should be addressed: Allison Roberto da Silva, RN

e-mail:

umberto@infonet.com.br

Available at:

http://www.archpedneurosurg.com.br/

\begin{abstract}
Introduction: Ventriculoperitoneal shunt (VPS) is a neurosurgical intervention widely used in the control and treatment of hydrocephalus. The migration of the peritoneal catheter through the abdominal wall is an uncommon complication and its pathophysiology is unknown.

Patients and Methods: Two cases of the peritoneal catheter extrusion through the abdominal wall are reported in patients with congenital hydrocephalus.

Results: Were discovered after removal of the bypass system and systemic antibiotic therapy, followed by replacement of new bypass, with excellent results.

Conclusion: In the presence of this complication, surgical treatment is indicated, through complete removal of the system, systemic antibiotic therapy and subsequent replacement of a new system.
\end{abstract}

Keyworks: Abdominal wall; complications; hydrocephalus; Ventriculoperitoneal shunt.

\section{INTRODUCTION}

Ventriculoperitoneal shunt (VPS) is a neurosurgical intervention indicated for the control and treatment of hydrocephalus [1]. The most common complications of this procedure are: erosion of the skin at the valve site, edema along the catheter path [2], infections [3], malfunction mechanical system [4], disconnection and subdural hematoma [5]. Abdominal complications resulting from the distal catheter are: obstruction of catheter [2], fracture and/or disconnection [5], migration [6], abscess [3], abdominal wall cyst [4], perforations in intestine [3]; bladder [5]; and scrotum [7], and extrusion of the catheter through the vagina [8]; anus [4]; lumbar; and cervical region [6].

Extrusion of the peritoneal catheter through the abdominal wall has been considered rare [1]. Its treatment includes removal of the catheter, systemic antibiotic therapy and replacement of a new system device [9].
The authors describe two cases of the peritoneal catheter spontaneous extrusion through the abdominal wall, discussing its pathophysiology, diagnosis, treatment and prognosis.

\section{PATIENTS AND METHODS}

Retrospective study of two patients who presented peritoneal catheter spontaneous extrusion through the abdominal wall, admitted at Emergency Hospital (Aracaju Sergipe, Brazil). The following aspects were analyzed: age, sex, predisposing causes, clinical history, pathophysiology, diagnosis, treatment and prognosis.

\section{RESULTS}

Case one

Newborn, male, six months old. He underwent VPS four months ago due to congenital hydrocephalus associated with aqueductal stenosis. He was admitted to the pediatric 


\section{Spontaneous extrusion of the peritoneal catheter through the intact abdominal wall: report of two cases}

emergency service in a poor general condition. Febrile associated with the presence of an erythematous lesion close to the umbilical scar, with spontaneous drainage of purulent secretion. Prominent anterior fontanelle. Presence of the distal portion of the catheter through the abdominal wall (Figure 1). The all VPS system was removed and during the systemic antibiotic therapy was performed an external ventricular drainage in frontal region. Bacterioscopy of purulent secretion and cerebral spinal fluid (CSF) presented negative culture. After seven days of antibiotic treatment, a new VPS system with a medium pressure valve was installed in the opposite site of the first VPS. He was discharged from hospital with normotensive fontanelles and improved general condition. The family was oriented for outpatient follow-up.

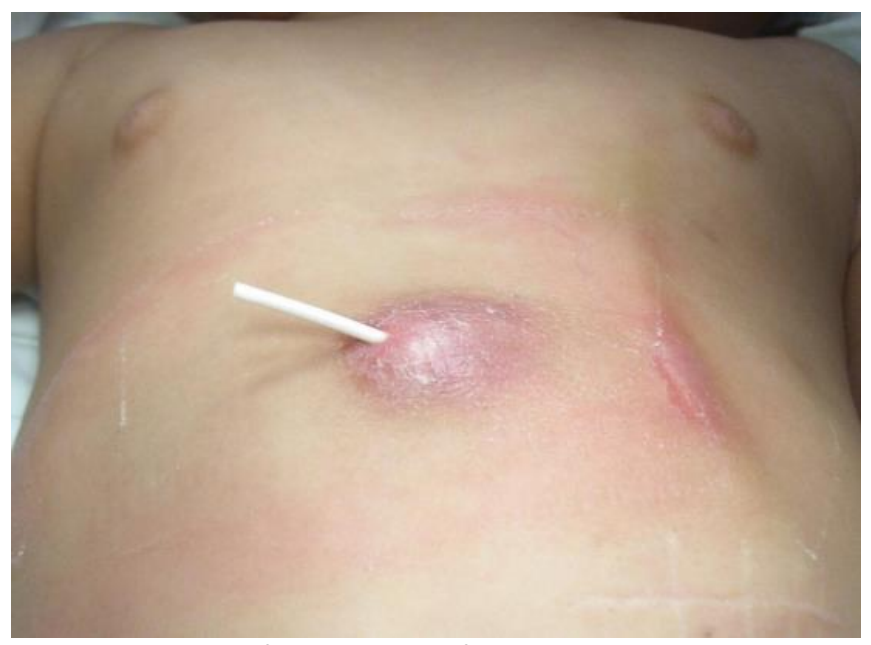

Figure 1 - Presence of the distal end of the peritoneal catheter extrusion, close to the umbilical scar.

\section{Case two}

Newborn, male, four months old. He was submitted to VPS three months ago due to congenital hydrocephalus associated with aqueductal stenosis. He entered the emergency room in a very poor general condition, feverish and malnourished. He had inflammatory signs in the abdominal wall associated with extrusion of the peritoneal catheter (Figure 2). He was submitted to systemic antibiotic therapy and removed from all the VPS system, being submitted to an external ventricular drain in the frontal region, after eight days he was submitted to a new VPS on the opposite side. He was discharged from hospital after 12 days, with a well-functioning and without fever.

\section{DISCUSSION}

\section{Etiology}

The abdominal complications associated with the peritoneal catheter vary between $10 \%$ and $30 \%$ of all cases

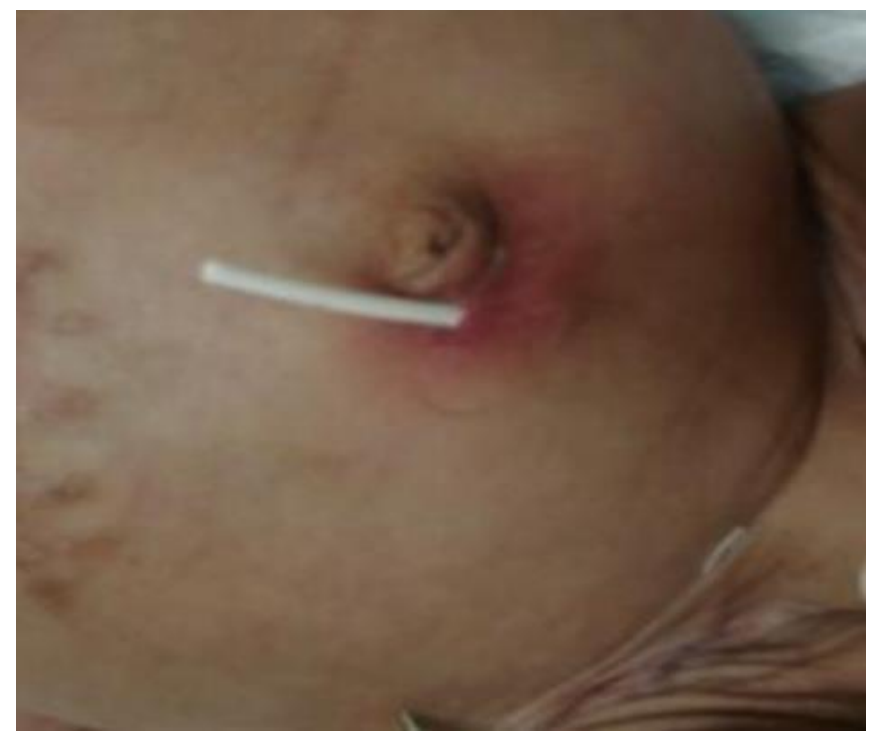

[10]. Extrusion of the peritoneal catheter through the abdominal wall is rare [1]. While the proximal portion of the catheter can migrate into the blood [5], it can cause distal

Figures 2. Extrusion of the peritoneal catheter distal end into the abdominal wall.

complications such as: extrusion of the catheter via umbilical scar [6], abdominal wall, vagina, urethra and anus [9].

\section{Physiopathology}

Its pathophysiology is still unknown. The likely predisposing factors for this complication are: infection, obstruction or displacement of the catheter and peritoneal foreign body reaction $[11,12]$. One hypothesis is the continuous "hammer effect" caused by the constant pulsations of cerebrospinal fluid on the abdominal wall [1].

The flexion-extension movement of the head can act as a "reel", facilitating the upward movement of the peritoneal catheter, and the anchorage prevents the return to the peritoneal cavity, migrating to the subcutaneous area of the skin. In addition, scalp mobility can allow the catheter to slide, or increase the upward movement of the peritoneal catheter. Additionally, the peristaltic movements of the intestine, the omental and the intra-abdominal pressure start an activity adjuvant role, directly pressing the foreign body of the peritoneal cavity towards the skin $[13,14]$.

In our cases, in the first case, the type II of VPS migration occurred, the external migration [15], the probable mechanisms were due to the abdominal wall weakened by malnutrition. In the second case, it could be associated with the patient's poor general condition and infection.

\section{Symptomatology}

The clinical signs is the peritoneal end of the VPS externalized in the abdominal wall, this area may have 


\section{Spontaneous extrusion of the peritoneal catheter through the intact abdominal wall: report of two cases}

erythema, inflammation, tenderness and elimination of secretion around [1], and painless erythematous blister [9].

Diagnosis

Imaging exams for early detection of intraabdominal complications secondary to VPS include: simple radiography, ultrasound, computed tomography (CT) and magnetic resonance imaging [3]. An abdominal CT will present a distal end of the VPS penetrating an abdominal wall [1].

\section{Treatment}

Surgical treatment is indicated in this case and consists of removing the catheter via the extrusion site and subsequent removal of system [1]. Placing the catheter between the subcutaneous fat and the abdominal muscle wall helps to avoid this complication. Other options to treatment were: externalization of the distal catheter into an EVD, during treatment with antibiotics [1]; and, removing the entire VPS, following the antibiotic therapy, and after some days a new shunt system was inserted [9].

In these cases, once submitted to the removal of the system, systemic antibiotic therapy and subsequent replacement of a new derivation when necessary [9], presents an excellent result, a fact that occurred in our patients.

\section{CONCLUSION}

Extrusion of the distal catheter through the abdominal wall is a rare complication and the cause is not well defined. Its early recognition and proper management are associated with a good prognosis. Systemic antibiotic therapy and system withdrawal are essential to prevent the appearance of other complications.

\section{DISCLOSURES}

The authors report that there are no conflicts of interest to disclosure.

\section{REFERENCES}

1. Alolyani A, Al-Dandan F, Al-Umran S, Ammar A. Extrusion of anterior abdominal wall by a ventriculoperitoneal shunt - An uncommon complication: Case report and literature review. Asian J Neurosurg 2020; 15:425-427. DOI 10.4103/ajns.AJNS_347_19

2. Rehman L, Ilyas $M$, Khattak A, Mushtaq, Shah SDA. Ventriculoperitoneal shunt and its complications in children. Pak J Surg 2012; 28(2):93-7.

3. Chung J-J, Yu J-S, Kim JH, Nam SJ, Kim M-J. Intraabdominal complications secondary to ventriculoperitoneal shunts: CT findings and review of literature. AJR 2009; 1311-17. DOI:10.2214/AJR.09.2463

4. Barkatullah AM, Mahmood E, Barua KK, Alam MM. What should be the length of the peritoneal catheter in VP shunt? ORION Med J 2004; 21:279-80.

5. Rahalkar MD. Complications of cerebroespinal fluid diversion (Shunt) catheters: A pictorial essay. Indian J Neurosurg 2018; 7:58-76.

6. Kanojia R, Sinha SK, Rawat J, Wakhlu A, Kureel S, Tandon R. Unusual ventriculoperitoneal shunt extrusion: Experience with 5 cases and review of the literature. Pediatr Neurosurg 2008; 44:49-51.

7. Pereira CU, Silva AD, Barreto AS, Duarte GC, Braz PC. Peritoneal catheter extrusion through the scrotal sac. Case report. Rev Chil Neurocir 2002; 18:70-71.

8. Pereira CU, Silva AD, Gonzaga AKV, Santos J. Extrusão do cateter peritoneal pela vagina. Arq Bras Neurocir 1999; 18:49-50.

9. Dağtekin A, Karabağ $H$, Avcı E, Naycı A, Bağdatoğlu C. A rare complication with ventriculoperitoneal shunt in pediatric cases. Ege J Med 2011; 50(1):65-8.

10. Bryant MS, Bremer AM. Abdominal complications of ventriculoperitoneal shunts. Case reports and literature review Am Surg 1988; 54:50-5.

11. Kaplan M, Ozel SK, Donmez O, Kazez A. Treatment approaches for abdominal migration of peritoneal catheter of ventriculoperitoneal shunt. Turk Neurosurg 2007; 17:158-62.

12. Borkar SA, Satyarthee GD, Khan RN, Sharma BS, Mahapatra AK. Spontaneous extrusion of migrated ventriculoperitoneal shunt catheter through chest wall. A case report. Turk Neurosurg 2008; 18:95-8.

13. Panigrahi S, Mishra SS, Das S, Tripathy L, Pattajoshi AS. Spontaneous extrusion of peritoneal catheter of ventriculoperitoneal shunt through the intact abdominal wall: Report of two cases. J Pediatr Neurosci 2012; 7:228-30.

14. Birbilis T, Theodoropoulous E, Matis G. Spontaneous externalization of peritoneal catheter through the abdominal wall in a patient with hydrocephalus: a case report. Cases J. 2009; 2:6898.

15. Allouh MZ, Al Barbarawi MB, Asfour HA, Said RS. Migration of distal catheter of the ventriculoperitoneal shunt hydrocephalus: A comprehensive analytical review from an anatomical perspective. Clinical Anatomical 2017; 00:00-00. 